ISSN 1981-416X

Licenciado sob uma Licença Creative Commons

\title{
A não inovação do programa Ensino Médio inovador
}

\author{
The non-innovation of the Ensino \\ Médio Inovador Program
}

\author{
La no innovación del Programa \\ Ensino Médio Inovador
}

\section{Silvia Cristina Conde Nogueira, Pedro Rodolfo Fernandes da Silva, Thayná Gundin Gadelha*}

Universidade Federal do Amazonas (UFAM), Manaus, AM, Brasil

\section{Resumo}

O Programa Ensino Médio Inovador (PROEMI) objetiva o desenvolvimento de propostas curriculares inovadoras em escolas de Ensino Médio. Entretanto, trabalhos acadêmicos e observação da realidade de uma escola da zona de norte de Manaus revelam os óbices desse programa. Nesse contexto, a partir do conceito de paradoxo lógico, que implica a existência de duas proposições contraditórias advindas de premissas reconhecidas como verdadeiras, apresenta-se o paradoxo da não inovação do Programa Ensino Médio Inovador. Nesse sentido, o artigo visa problematizar esse paradoxo com o intuito de ensejar a discussão acerca dos limites dessa política educacional. Para tal, efetuou-se a revisão

"SCCN: Doutora em Educação, e-mail: silviaconde@uol.com.br PRFS: Doutor em Filosofia, e-mail: pedrofernandes845@gmail.com TGG: Graduada em Pedagogia, e-mail: thaynag.gadelha@gmail.com 
de literatura, a pesquisa documental, a pesquisa de campo e a análise dos dados, a partir das categorias da totalidade, da contradição e da mediação. Comparam-se os argumentos que sustentam a inovação e os contrários por meio de documentos do Ministério da Educação, das teses, das dissertações e da realidade observada em uma escola de Manaus. A análise das contradições do PROEMI viabilizou a conclusão de que uma política governamental que propõe promover a melhoria da qualidade da Educação, com ações restritas de reestruturação curricular e readequação de práticas pedagógicas, em nada inova na solução de problemas sócio-históricos relacionados ao Ensino Médio, pois traz consigo problemas como a distorção idade/série, a evasão dos alunos e os baixos índices alcançados nas avaliações nacionais.

Palavras-chave: Programa Ensino Médio Inovador. Reestruturação Curricular. Ensino Médio.

\section{Abstract}

The Ensino Médio Inovador Program (Innovative High Sch'ool Program - PROEMI) aims to develop innovative curricula in high schools. However, academic works and the observation of the reality of a school in the northern zone of Manaus reveal the obstacles of this program. In this context, from the concept of logical paradox that implies the existence of two contradictory propositions coming from premises recognized as true, the paradox of non-innovation of the Ensino Médio Inovador Program is presented. In this sense, the article aims to problematize this paradox with the purpose of enticing the discussion about the limits of this educational politics. For this, it was affected the literature review, the documentary research, the field research and the analysis of the data from the categories of totality, contradiction, and mediation. The arguments that support innovation and the arguments opposites were compared by means documents of the Ministry of Education, of the theses, of the dissertations and of the reality observed in a school in Manaus. The analysis of the contradictions of PROEMI enabled the following conclusion: a government politics that proposes to promote the improvement of the quality of education with restricted actions of curricular restructuring and readjustment of pedagogical practices does not innovate in the solution of socio-historical problems related to secondary education, 
because brings with it problems like the distortion age/grade school, student evasion and low indices achieved in national assessments.

Keywords: Ensino Médio Inovador Program. Curricular Restructuring. High School.

\section{Resumen}

El Programa Ensino Médio Inovador (Programa Enseñanza Media Innovadora - PROEMI) tiene como objetivo el desarrollo de propuestas curriculares innovadoras en escuelas de enseñanza media. Entretanto, trabajos académicos y la observación de la realidad de una escuela de la zona norte de Manaos revelan los óbices de ese programa. En este contexto, a partir del concepto de paradoja lógico que implica la existencia de dos proposiciones contradictorias surgidas de premisas reconocidas como verdaderas, se presenta la paradoja de la no innovación del Programa Ensino Médio Inovador. En este sentido, el artículo tiene por objetivo problematizar esta paradoja con el propósito de dar lugar a la discusión acerca de los límites de esa política educativa. Para esto, se efectuó la revisión de la literatura, la investigación documental, la investigación de campo y el análisis de los datos a partir de las categorías de la totalidad, de la contradicción y de la mediación. Fueron comparados los argumentos que sostienen la innovación y los contrarios por medio de documentos del Ministerio de Educación, de las tesis, de las disertaciones y de la realidad observada en una escuela de Manaus. El análisis de las contradicciones del PROEMI permitió la siguiente conclusión: una política gubernamental que propone promover la mejora de la calidad de la educación con acciones restringidas de reestructuración curricular y readecuación de prácticas pedagógicas en nada innova en la solución de problemas socio históricos relacionados a la enseñanza media, porque trae consigo problemas como la distorsión edad/serie, la evasión de los alumnos y los bajos índices alcanzados en las evaluaciones nacionales.

Palabras clave: Programa Ensino Médio Inovador. Reestructuración Curricular. Enseñanza Media. 


\section{Introdução}

A centralidade deste artigo consiste em analisar os limites e as possibilidades do Programa Ensino Médio Inovador (PROEMI). O desenvolvimento desta análise fundamenta-se na concepção de que tal Programa, embora trouxesse como proposta a inovação do Ensino Médio, indica, tanto em sua concepção quanto em sua implementação, sua não inovação, o que revela a existência de um paradoxo lógico na medida em que

[...] um paradoxo lógico consiste em duas proposições contrárias ou contraditórias derivadas conjuntamente a partir de argumentos que não se revelaram incorretos fora do contexto particular que gera o paradoxo. Ou seja, partindo de premissas geralmente aceitas e utilizadas, é (pelo menos aparentemente) possível, em certas condições específicas, inferir duas proposições que ou afirmam exatamente o inverso uma da outra ou não podem ser ambas verdadeiras (BRANQUINHO, 2006, p. 573).

Nesse sentido, observam-se duas proposições contraditórias, autoexcludentes, acerca de uma política educacional para o Ensino Médio: 1) a proposição de não inovação emerge do título "Programa Ensino Médio Inovador", adjetivando a última etapa da Educação Básica, pelo qual o Ministério da Educação propõe “[...] um programa de apoio para promover inovações pedagógicas das escolas públicas [...] objetivando o fomento de mudanças que se fazem necessárias na organização curricular do Ensino Médio" (BRASIL, 2009); 2) a outra proposição emerge dos resultados da pesquisa intitulada "PROEMI: marcos legais, pesquisas acadêmicas e a realidade de uma escola de Manaus", realizada no ano de 2017.

Desse modo, a inovação do referido programa está relacionada à implementação de novos processos no cotidiano escolar. Sendo assim, o conceito de inovação do programa relaciona-se ao campo da economia, pois, conforme Lazzarotti, Dalfovo e Hoffmann (2011, p. 122) o economista Schumpeter, ao abordar o desenvolvimento econômico em 1934, definiu inovação "[...] como a formação de novos produtos ou serviços, novos processos, matérias-primas, novos mercados e novas organizações [...]”. 
A identificação desse aporte teórico é fundamental para sustentar que o paradoxo da não inovação do Programa Ensino Médio Inovador é de natureza conceptual e também da ordem da implementação. Para problematizá-lo, inicialmente apresentam-se os argumentos que sustentam a inovação do Programa a partir dos documentos do Ministério da Educação e de algumas dissertações e teses ${ }^{1}$. Em seguida, apontam-se os argumentos de não inovação apresentados nas dissertações e teses e, finalmente, sob as premissas acerca da natureza do paradoxo discutem-se as contradições do PROEMI.

\section{O Programa Ensino Médio Inovador: as concepções governamentais e os resultados de pesquisas}

O PROEMI, sob o discurso governamental, visa promover propostas curriculares inovadoras em escolas de Ensino Médio, por meio de apoio às Secretarias Estaduais de Educação e do Distrito Federal no desenvolvimento de ações de melhoria da qualidade dessa etapa de ensino, propondo que as inovações curriculares ocorram a partir da realização de projetos pedagógicos que promovam a educação científica e humanística (MEC, 2009). Além disso, tem como objetivo melhorar a qualidade do Ensino Médio nas escolas públicas estaduais, promovendo a superação das desigualdades de oportunidades educacionais, a universalização do acesso e permanência dos sujeitos de 15 a 17 anos no Ensino Médio, a consolidação da identidade do Ensino Médio, sem perder de vista a diversidade dos sujeitos e a aprendizagem significativa para jovens e adultos, reconhecendo e priorizando o diálogo com as culturas juvenis (MEC, 2009).

O PROEMI surge como resposta aos seguintes desafios: adoção de diferentes formas de organização curricular; identidade unitária

1 Levantamento realizado entre maio e agosto de 2017 no site da Biblioteca Brasileira de Teses e Dissertações: <http://bdtd.ibict.br/vufind/>. Foram identificados 43 trabalhos que em seus títulos faziam referência ao PROEMI. Após a leitura dos resumos, identificou-se 16 trabalhos que abordavam as concepções acerca do programa. Esses trabalhos foram codificados e classificados em dois grupos: os consensos pela inovação e as controvérsias da inovação do programa. 
articulando trabalho, ciência e cultura; superação da dicotomia humanismo x tecnologia; formação teórica x formação técnico instrumental (MEC, 2009).

O Programa tem como linhas de ação o fortalecimento da gestão dos sistemas; fortalecimento da gestão escolar; melhoria das condições de trabalho docente e formação continuada; apoio às práticas docentes; desenvolvimento do protagonismo juvenil; apoio ao aluno jovem adulto trabalhador; infraestrutura física e recursos pedagógicos, além de elaboração de pesquisas sobre o Ensino Médio e a juventude (MEC, 2009).

A operacionalização do Programa consiste no regime de colaboração entre a União, os Estados, o Distrito Federal e os Municípios. A União tem a responsabilidade na criação de propostas inovadoras e na garantia de condições materiais e financeiras para as mudanças curriculares. Os governos dos Estados e do Distrito Federal, por meio do Termo de Adesão, aceitam as diretrizes, as metas e os procedimentos operacionais e encaminham ao MEC o Plano de Ação Pedagógica das escolas participantes. A Diretoria de Concepções e Orientações Curriculares para a Educação Básica (DCOCEB) é responsável pelo monitoramento e avaliação do Programa (MEC, 2009).

A centralidade do PROEMI consiste na proposição de reestruturação curricular. Entre 2009 e 2016, foram produzidos documentos - o Documento Orientador (MEC 2009) e as Resoluções nº 63 (FNDE, 2011), $\mathrm{n}^{\circ} 31$ (FNDE, 2013), nº 04 (FNDE, 2016) 2 - que revelam quatro versões de organizações curriculares possíveis para as escolas.

O Documento Orientador (MEC, 2009) estabeleceu que o tratamento curricular deveria considerar as condições de aumento gradativo de 600 horas na jornada escolar; foco na leitura; utilização de laboratórios; atividades de produção artística; atividades optativas articuladas aos componentes curriculares obrigatórios; carga horária integral dos docentes nas escolas; organização curricular articuladas aos exames nacionais.

2 Essas resoluções destinam recursos financeiros, por meio do Programa Dinheiro Direto na Escola (PDDE) às escolas públicas selecionadas pelas secretarias estaduais de educação que aderiram ao PROEMI. 
As resoluções definem o que deve compor os Projetos de Reestruturação Curricular que, em 2013, foram substituídos por Projetos de Redesenho Curricular. Esses projetos consistem em organizações curriculares a serem estabelecidas por meio de macrocampos. Esses macrocampos, que podem ser obrigatórios ou eletivos, referem-se às Linguagens, à Iniciação Científica, às Artes, à Juventude, à Comunicação.

Na versão vigente, desde 2016, os Projetos de Redesenho Curricular devem apresentar ações em consonância com os campos: I-Acompanhamento Pedagógico (Língua Portuguesa e Matemática); II - Iniciação Científica e Pesquisa; III - Mundo do Trabalho; IV - Línguas Adicionais/Estrangeiras; V Cultura Corporal; VI - Produção e Fruição das Artes; VII - Comunicação, Uso de Mídias e Cultura Digital; e VIII - Protagonismo Juvenil.

São obrigatórios os campos de integração curricular I, II, III e VIII. Com exceção do campo I, as Secretarias de Educação podem substituir um dos campos obrigatórios pelo IV ou V ou VI ou VII. Dessa forma, as ações irão se referir a quatro campos de integração curricular obrigatórios e as escolas deverão selecionar mais um de sua preferência (FNDE, 2016).

Os documentos governamentais do PROEMI, ao pressupor que mudanças significativas no currículo das escolas públicas revertem problemas históricos do Ensino Médio, determinam como essas escolas devem organizar seus currículos: "fomentar as bases para uma nova escola de Ensino Médio” (MEC, 2009, p. 7).

Nesse contexto, serão abordadas uma série de pesquisas que evidenciam um consenso quanto ao caráter inovador do Programa, com o intuito de apresentar ao leitor os elementos que engendram tal proposição. No final deste artigo, estas pesquisas serão retomadas para melhor fundamentar as conclusões.

Camargo (2015), ao estudar a formação ofertada pelo Unibanco aos supervisores da parceria PROEMI/Jovem de Futuro, assevera que o PROEMI propõe maior integração entre a escola e a comunidade. Segundo ele, tal Programa visa uma mudança no fazer pedagógico da escola e estimula uma reflexão acerca do currículo e de suas necessidades. Para o autor, essas preocupações também são objeto de intervenção das organizações 
não governamentais. Nesse sentido, conclui que a parceria com o Unibanco complementa as ações do PROEMI e potencializa os seus resultados.

Pinto (2016), em seu estudo sobre a análise do papel do professor articulador de projetos e sua equipe pedagógica no PROEMI, revela que o Programa garante a maior participação dos agentes educacionais (professores, equipe pedagógica), tornando-os peça fundamental no processo de inovação desta etapa, por meio do trabalho interdisciplinar. Ainda conforme a autora, o Programa é uma nova proposta acerca de práticas pedagógicas exitosas para tornar esta etapa da educação mais atrativa.

Mofacto (2014), em seu estudo sobre a formação de supervisores provenientes da parceria PROEMI/Jovem do Futuro, apresenta a relação entre MEC e Instituto Unibanco. Para a autora, o Programa Jovem do Futuro deve ter ações de acordo com o que regulamenta o PROEMI, reforçando a ideia de complementação entre as duas propostas: o novo currículo do Ensino Médio e a gestão voltada para resultados.

Corrêa (2016), em estudo sobre a formação de professores de Matemática pelo curso de Licenciatura em Ciências Exatas da Universidade Federal do Paraná (UFPR) e suas articulações com as qualidades necessárias ao professor para atuar no Ensino Médio Brasileiro, especialmente no PROEMI, frisa que o PROEMI é um modelo de formação inovadora que revela um grande desafio em sua implementação, pois preocupa-se mais com a formação humana do que com o mero repasse de conteúdos técnicos. Porém, não deixa a transmissão de conteúdos em segundo plano, visto que a qualidade da formação humana está integrada, também, ao domínio desses conteúdos. Assim, destaca a necessária formação dos professores para a efetiva transmissão de conhecimento.

Figueiredo (2015), ao estudar o PROEMI em duas escolas públicas do Distrito Federal, afirma que o programa é uma proposta de política pública de enfretamento aos baixos índices educacionais do Ensino Médio e apresenta-se como inovador do currículo dessa etapa, tornando mais efetivo o aprendizado, mas sem esquecer as particularidades dos estudantes. O PROEMI inovou o modo de organização curricular e escolar 
do Ensino Médio, dando voz à toda a comunidade escolar, respeitando o contexto de diversidade e pluralidade existente na escola.

Rocha (2016), ao analisar a formação de professores frente às práticas inovadoras do PROEMI nas escolas, revela que o Programa apresenta o desafio focado em professores e estudantes na busca do desenvolvimento de novos conhecimentos. A autora conclui que o Programa tem como proposta inovadora uma reconfiguração das escolas públicas, por meio de seu currículo e da prática docente. Por isso a necessidade emergente de formação continuada dos professores.

Castro (2017), ao analisar a gestão escolar e a melhoria na aprendizagem dos estudantes a partir do PROEMI, em uma escola de Ensino Médio no Pará, revela que o programa é fruto de parcerias entre o MEC, a SEDUC e o Instituto Unibanco na busca de melhorias educacionais preocupadas, sobretudo, com a realidade particular de cada escola. Conforme a autora, o PROEMI tem como foco a eficácia dos serviços voltados para resultados positivos, por isso o estabelecimento de parceria público-privada (oferta de serviço).

Jakimiu (2014), em seu estudo sobre análise à indução do redesenho curricular para o Ensino Médio a partir do PROEMI, revela que o Programa provoca um debate com os Sistemas e Distritos de ensino em busca de uma inovação curricular para as escolas, apresentando um currículo menos fragmentado e disciplinarizado e, por isso, a perspectiva de campos de integração curricular. Ainda, segundo a autora, o PROEMI é uma proposta desafiadora à formação de professores, que supera as práticas tradicionais ensinadas nas instituições.

Isleb (2014), em estudo sobre o PROEMI e suas possibilidades de intervenção no fluxo escolar (reprovação e abandono), afirma que o PROEMI é considerado um indutor de redesenhos curriculares que podem auxiliar o processo de reeducação dos olhares dos profissionais da educação e trazer diferentes intervenções para a escola do Ensino Médio, contribuindo para a continuidade e para a ampliação de suas contribuições na organização curricular das escolas e nos dados do fluxo escolar das escolas participantes.

Os trabalhos apresentados evidenciam que os argumentos utilizados para a suposta inovação foram os mesmos apontados nos 
documentos do MEC: reconfigurações curriculares e práticas pedagógicas diferenciadas. Sendo assim, a inovação diz respeito à mudança na gestão dos processos de ensino-aprendizagem, pois o MEC pensa a melhor forma de organização curricular, sob a qual as propostas das escolas devem ser enquadradas, para que os professores, por meio de novas práticas, executem-na de modo que o efeito linear propiciará um novo Ensino Médio.

\section{Ensino Médio não inovador}

A proposição de não inovação do PROEMI consiste na posição defendida pelos autores deste trabalho. Para que a discussão não seja antecipada à fundamentação de tal proposição, esta seção se limitará a apresentar os resultados das pesquisas acadêmicas materializadas na Biblioteca Brasileira de Teses e Dissertações.

Mantovani Dias (2016), em estudo sobre o fortalecimento da profissionalização precoce dos jovens que frequentam o Ensino Médio público regular, revela que o PROEMI não apresenta uma nova concepção de Ensino Médio nem difere do que já vem posto pela LDB ou Diretrizes Curriculares. Pelo contrário, ele é apenas um programa que visa uma prática pedagógica mais atrativa, por meio do currículo, levando em consideração o protagonismo juvenil, relacionado ao melhor desempenho e atuação dos estudantes em função de sua aprendizagem.

Nogara Junior (2015), em estudo sobre o alinhamento do PROEMI e segundo as conjecturas do Banco Mundial, conclui que o PROEMI tem como objetivo mascarado fazer da juventude a nova válvula de escape da crise econômica, favorecendo, portanto, formas de trabalho precarizadas e estabilidade financeira e empregatícia quase nulas, devido à utilização do jovem como mão de obra barata.

Engelmann (2016), em análise da trajetória do Ensino Médio público brasileiro - do início da escolarização pública institucionalizada, no 
Período Colonial, até a implantação do PROEMI —, identifica que o programa é uma proposta oportunista do governo de apresentar um redesenho curricular, que, na prática do próprio programa, não acontece de fato. Tudo isso na tentativa falha de apresentar uma saída frente à atuação insuficiente do Estado quanto à essa etapa de ensino. O autor conclui que o PROEMI não oferece às escolas o suporte necessário para a sua realização, no que se refere não somente à oferta de recursos e à execução dos projetos conforme as propostas dos Projetos de Redesenho Curricular, mas à sua operacionalização, por meio de quantitativo de pessoal necessário para a sua prática.

Machado (2016), em estudo sobre o redesenho curricular a partir do PROEMI, chega à conclusão que o PROEMI é uma atividade paralela aos demais eventos que ocorrem na escola, sem seguir o real sentido da proposta, que é a reinvenção do currículo do Ensino Médio. Conforme a autora, o PROEMI é pautado em modelos de organismos internacionais a fim de garantir uma maior qualidade da Educação. Tal programa é idealizado na perspectiva de nivelamento da Educação Básica, tomando o currículo, a formação de professores e o tempo de permanência na escola como fundamentos basilares de alcance de qualidade da Educação, mas que não recebe suporte necessário na prática.

Matos (2015), em estudo sobre o PROEMI e sobre a relação curricular inovadora de integração revela que o programa desconsidera fatores "antigos" como a formação de professores e valorização docente segundo suas condições de trabalho, estrutura das escolas e a própria realidade dos alunos.

Ferreira (2015), em estudo sobre o PROEMI na legislação educacional e as contribuições dele para a melhoria do Ensino Médio, assevera que o PROEMI está centrado na indução da construção de novos currículos, para que possa envolver todos os sujeitos da escola. Os recursos, por sua vez, são estímulos para que o programa se efetive no chão da escola, porém, o suporte financeiro do PROEMI não é suficiente para promover as mudanças orientadas pelo programa.

Majeski (2013), em seu estudo sobre as políticas públicas para o Ensino Médio, destaca que o PROEMI foi criado com o objetivo de melhorar a qualidade da Educação, possibilitando novos caminhos para o 
Ensino Médio, a julgar pelas particularidades de cada aluno, mas não se articula com as propostas elencadas pelas próprias Diretrizes Curriculares Nacionais, com o mesmo fim. Ainda segundo a autora, o programa precisa oferecer maior estrutura para as escolas, além de condições de trabalho que incluam a formação continuada dos professores adeptos ao projeto.

Os trabalhos apresentados nesta seção enfatizam que a centralidade do PROEMI na reconfiguração curricular é um limite para o enfrentamento dos problemas historicamente estabelecidos no Ensino Médio. Ademais, advertem sobre os problemas na operacionalização do programa, como a insuficiência de recursos e a realização de atividades paralelas ao currículo das escolas. Destacaram, ainda, a falta de condições de trabalho, da escola, dos professores e dos alunos.

\section{Considerações finais}

O Programa Ensino Médio Inovador (PROEMI), ao induzir ações exclusivamente voltadas para a reconfiguração curricular evidencia uma concepção de inovação que se inclina à gestão e à organização de processos. De modo geral, tal inovação faz um rearranjo de fatores já existentes para produzir uma nova realidade. No âmbito da geração de lucros, a inovação é um fator econômico importantíssimo, pois pode assegurar uma mudança na realidade bastante rentável. Porém, no que se refere à Educação, a inovação não deve ser pensada em termos de rentabilidade, pois a Educação não é mercadoria. A rentabilidade não pode, ainda, ser pensada exclusivamente em termos de melhoria de índices avaliativos, sob pena de reduzir a Educação ao alcance de resultados, eliminando-se a concepção de Educação como processo de formação humana.

As ações inovadoras do PROEMI, centradas na reconfiguração curricular, não enfrentam os problemas históricos do Ensino Médio, como a distorção idade/série, a evasão escolar e os baixos índices nas avaliações nacionais. Sobre esses dados, destaca-se que o Ensino Médio brasileiro apresenta taxa de distorção idade/série de 28, 2\% (INEP, 2017). No que 
se refere às taxas de evasão dos alunos dessa etapa da Educação Básica, entre 2014 e 2015, essas taxas corresponderam à 12,9\% dos alunos matriculados na $1^{\mathrm{a}}$ série; $12,7 \%$ dos alunos matriculados na $2^{\mathrm{a}}$ série; e $7,7 \%$ dos alunos matriculados na $3^{\mathrm{a}}$ série (INEP, 2017).

Quanto aos índices alcançados nas avaliações nacionais, em 2017, somente 1,6 \% dos estudantes do Ensino Médio, que participaram do Sistema de Avaliação da Educação Básica (SAEB), foi classificado nos níveis que indicam "aprendizagem adequada" em Língua Portuguesa. Em Matemática esse índice foi de, aproximadamente, 4,5\%.

Infere-se que o enfrentamento desses desafios extrapola mudanças restritas ao âmbito dos currículos, pois essas mudanças só têm o significado de inovação em contextos muito específicos, como por exemplo na economia em que inovação é entendida como geração de novos produtos ou processos. Entretanto, no contexto brasileiro, as mudanças de currículo do Ensino Médio propostas pelo PROEMI tendem a reduzir a concepção de inovação às mudanças na oferta de disciplinas, o que não provoca mudanças necessárias e urgentes para a última etapa da Educação Básica.

$\mathrm{Na}$ realidade, são essenciais as mudanças estruturais na economia política vigente. Essas mudanças possibilitariam a efetivação plena de uma Educação Pública, gratuita e socialmente referenciada. Sob essa perspectiva, a concepção de inovação vai além da reconfiguração curricular; provoca as mudanças necessárias para as condições objetivas de ensino e aprendizagem; transforma as condições de trabalho e de estudo; e articula-se às concepções de politecnia e omnilateralidade.

Sob essas perspectivas haveria inovação, pois a politecnia conforme Saviani (2003) - refere-se ao desenvolvimento multilateral; pressupõe a união entre instrução intelectual e trabalho produtivo; diz respeito à tradição socialista; e inova porque é o contraponto à concepção burguesa de Educação. Nesta mesma direção, a omnilateralidade, como processo formativo humano oposto ao processo de formação unilateral 
engendrado na sociedade capitalista, inovaria os processos educativos combatendo o trabalho alienado e a divisão social do trabalho ${ }^{3}$.

Uma vez demonstrado que o paradoxo da não inovação do Ensino Médio tem natureza conceptual, o paradoxo na implementação do programa torna-se uma consequência lógica: a inovação no processo de ensino-aprendizagem restrita às alterações formais curriculares e de práticas pedagógicas provoca pequenas mudanças no cotidiano da realidade escolar, sem efeitos significativos nas escolas de Ensino Médio.

Outrossim, os dados da realidade trazidos pelos pesquisadores abordados revelam as realidades escolares perpassadas por contradições que inviabilizam as ações previstas no PROEMI, ou seja, há dificuldades para as inovações de processos. Algumas dessas dificuldades podem ser confirmadas nas observações feitas durante a pesquisa de campo que acompanhou parte da execução das ações do PROEMI em uma escola de Manaus.

A referida escola fica na zona norte de Manaus e atende exclusivamente estudantes do Ensino Médio, além de apresentar infraestrutura razoável para acolhimento desses jovens. Em 2017, 2.734 alunos estavam matriculados, divididos nos três turnos. Segundo dados do Censo Escolar de 2017 (INEP, 2018b), a escola apresentou as seguintes taxas de distorção idade/série: $43,1 \%$ no primeiro ano, $31,8 \%$ no segundo ano e $26,6 \%$ no terceiro ano.

Realizou-se a observação direta nessa escola de Ensino Médio em 2017, no turno vespertino. Os registros em cadernos de campo e registros fonográficos documentam a realidade observada e demonstram os entraves para a implementação do PROEMI: na falta de pedagogo no turno vespertino, o professor articulador do PROEMI assumiu a função de apoio pedagógico da escola; dos Campos de Integração Curriculares ${ }^{4}$ adotados na Escola ficou evidente a realização de atividades referente ao campo de Produção e Fruição das Artes; o projeto executado teve pouca participação dos professores da escola; a maioria dos professores,

3 Inferência inspirada no conceito de omnilateralidade apresentado por Sousa Junior (2008).

4 Acompanhamento Pedagógico (Língua Portuguesa e Matemática), Iniciação Científica e Pesquisa, Mundo do Trabalho e Protagonismo Juvenil e Produção e Fruição das Artes. 
também, trabalhava em outras escolas; na ausência de professores, os alunos eram liberados e ficavam no entorno da escola.

Esses resultados, mais do que problemas para a implantação do PROEMI, indicam os desafios do cotidiano escolar de uma boa parte das escolas públicas brasileiras e indicam os limites de um programa, que propõe promover a melhoria da qualidade da Educação com ações restritas de reestruturação curricular e readequação de práticas pedagógicas.

O paradoxo da não inovação do Programa Ensino Médio Inovador foi apresentado para a discussão dos limites de uma política governamental que tem a pretensão de inovação, restringindo-se aos processos de reorganização curricular a ser implementado mediante novas práticas pedagógicas.

A identificação do aporte teórico-metodológico desse programa no campo da economia foi fundamental para apontar a natureza conceptual do paradoxo. Essa natureza mostra-se confirmada quando se discute os problemas na realidade objetiva do Ensino Médio, os quais não são passíveis de resoluções por meio de arranjos no currículo. Não obstante, a concepção de inovar por meio de processos pode levar a caminhos mais distantes dos ideais de Educação pública e gratuita quando algumas pesquisas apontam resultados positivos de organizações não governamentais, como o UNIBANCO, na implementação do PROEMI.

Ademais, a realidade da evasão escolar, da distorção idade/série, dos baixos índices de rendimento nas avaliações externas, das condições precarizadas de trabalho e de estudo exigem uma nova economia política em que a Educação politécnia e omnilateral seja a inovação concreta, integrando as dimensões do trabalho, da ciência, da tecnologia e da cultura.

\section{Referências}

BRANQUINO, J. Enciclopédia de Termos Lógico-filosóficos. São Paulo: Martins Fontes, 2006. 
BRASIL. Conselho Nacional de Educação (CNE). Parecer Homologado. Despacho do Ministro, publicado no D.O.U. de 25/8/2009. Seção 1, p. 11. Disponível em: <http://portal.mec.gov.br/index.php?option=com_docman\&view=download\&alias=3905-02-parecer-n-11\&category_slug=marco-2010-pdf\&Itemid=30192 >. Acesso em: 23 dez. 2017.

BRASIL. Ministério da Educação (MEC). Portaria $n^{0}$ 971, de 9 de outubro de 2009, pela qual o Ministro da Educação institui o Ensino Médio Inovador. Diário Oficial da União (DOU), de 13/10/2009, nº 195, Seção 1, pág. 52. Brasília, 2009.

CAMARGO, E. F. de. As formações no âmbito da parceria Programa Ensino Médio Inovador/Jovem do Futuro - PROEMI/JF. 2015. Dissertação (Mestrado em Gestão e Avaliação da Educação pública) — Universidade Federal de Juiz de Fora, Juiz de Fora, 2015.

CASTRO, M. R. de O. Uma experiência do Programa Ensino Médio Inovador em Ananindeua - Pará. 2017. Tese (Doutorado em Educação) — Universidade Federal do Pará, Pará, 2017.

CORRÊA, V. S. A. A formação do professor de matemática na licenciatura integrada em ciências exatas: possíveis articulações com o ensino médio inovador (PROEMI). 2016. Tese (Doutorado em Educação) - Universidade Federal do Paraná, Curitiba, 2016.

ENGELMANN, D. A. Dos (des)caminhos percorridos pelo Ensino Médio ao Programa Ensino Médio Inovador (PROEMI) - proposto pelo MEC. 2016. Dissertação (Mestre em Educação — Universidade Tuiuti, Curitiba, 2016.

FERREIRA, S. R. Financiamento da educação como indutor de política curricular: análise a partir da implantação do programa ensino médio inovador no Paraná. 2015. 149f. Dissertação (Mestrado em Educação) — Universidade Federal do Paraná, Curitiba, 2015.

FIGUEIREDO, K. J. A. A. Programa Ensino Médio Inovador - ProEMI: o que revelam as intenções de melhoria do ensino médio no Brasil: o caso do Distrito Federal. 2015. 243 f. Tese (Doutorado em Educação) — Universidade de Brasília, Brasília, 2015. 
FUNDO NACIONAL DE DESENVOLVIMENTO DA EDUCAÇÃO (FNDE). Resolução/FNDE/CD/n $/ n^{\circ}$ 63, de 16 de novembro de 2011. Autoriza destinação de recursos financeiros, em 2012, às escolas públicas estaduais e distritais de ensino médio que aderirem ao Programa Ensino Médio Inovador (PROEMI).

FUNDO NACIONAL DE DESENVOLVIMENTO DA EDUCAÇÃO (FNDE). Resolução/FNDE/CD $/ n^{\circ} 31$, de 22 de julho de 2013. Dispõe sobre a destinação de recursos financeiros, às escolas públicas dos Estados e do Distrito Federal de ensino médio que aderirem ao Programa Ensino Médio Inovador (PROEMI).

FUNDO NACIONAL DE DESENVOLVIMENTO DA EDUCAÇÃO (FNDE). Resolução/FNDE/CD/no 4, de 25 de outubro de 2016. Destina recursos financeiros, nos moldes operacionais e regulamentares do Programa Dinheiro Direto na Escola - PDDE, a escolas públicas estaduais e do Distrito Federal, a fim de apoiar e fortalecer o desenvolvimento de propostas curriculares inovadoras, em conformidade com o Programa Ensino Médio Inovador.

INSTITUTO NACIONAL DE ESTUDOS E PESQUISAS EDUCACIONAIS ANÍSIO TEIXEIRA (INEP). Em 2017, a taxa de distorção idade-série no Ensino Médio foi de 28,2\%. Censo Escolar, 2018. Disponível em: <http://portal.inep.gov.br/artigo/-/asset_publisher/B4AQV9zFY7Bv/content/dados-do-censo-escolar-rede-publica-tem-maior-numero-de-alunos-com-idade-acima-do-recomendado-para-a-serie-de-ensino/21206>. Acesso em: 20 ago. 2018.

INSTITUTO NACIONAL DE ESTUDOS E PESQUISAS EDUCACIONAIS ANÍSIO TEIXEIRA (INEP). Inep divulga dados inéditos sobre fluxo escolar na educação básica. Censo Escolar, 2017. Disponível em: <http://portal.inep.gov.br/artigo/-/ asset_publisher/B4AQV9zFY7Bv/content/inep-divulga-dados-ineditos-sobre-fluxo-escolar-na-educacao-basica/21206 >. Acesso em: 31 ago. 2018.

INSTITUTO NACIONAL DE ESTUDOS E PESQUISAS EDUCACIONAIS ANÍSIO TEIXEIRA (INEP). Indicadores educacionais. Disponível em: <http://portal.inep. gov.br/web/guest/indicadores-educacionais >. Acesso em: 27 ago. 2018. 
INSTITUTO NACIONAL DE ESTUDOS E PESQUISAS EDUCACIONAIS ANÍSIO TEIXEIRA (INEP). Sistema de Avaliação da Educação Básica: Evidências da Edição de 2017. Brasília: agosto, 2018. Disponível em: <http://portal.mec.gov.br/index. php?option=com_docman\&view=download\&alias=94161-saeb-2017-versao-ministro-revfinal\&category_slug=agosto-2018-pdf\&Itemid=30192 >. Acesso em: 31 ago. 2018.

ISLEB, V. O Programa Ensino Médio Inovador e sua relação com os dados de fluxo escolar. Dissertação (Mestrado em Educação) — Universidade Federal do Paraná, Curitiba, 2014.

JAKIMIU, V. C. de L. Políticas de reestruturação curricular no Ensino Médio: uma análise do Programa Ensino Médio Inovador. 2014. Dissertação (Mestrado em Educação) - Universidade Federal de Curitiba, Curitiba, 2014.

LAZZAROTTI, F.; SAMIR DALFOVO, M.; EMIL HOFFMANN, V. A Bibliometric Study of Innovation Based on Schumpeter. Journal of Technology Management \& Innovation, Santiago, v. 6, n. 4, p. 121-135, 2011. Disponível em: <https://scielo. conicyt.cl/scielo.php?script=sci_arttext\&pid=S0718-27242011000400010\&ln g=es\&nrm=iso >. Acesso em: 29 ago. 2018. http://dx.doi.org/10.4067/ S0718-27242011000400010.

MACHADO, A. K. M. N. Redesenhando o currículo do Ensino Médio: o caso do PROEMI na Escola Educandário Oliveira Brito - Euclides da Cunha/BA. 2016. Dissertação (Mestre em Educação) — Universidade Estadual de Feira de Santana, Feira de Santana, 2016.

MAJESKI, S. Ensino Médio, currículo e cotidiano escolar: sobre movimentos e tensões nos discursos oficiais. 2013. Dissertação (Mestrado em Educação) Universidade Federal do Espírito Santo,Vitória, 2013.

MANTOVANI DIAS, C. O trabalho como princípio educativo: uma análise do Programa Ensino Médio Inovador (PROEMI) nas escolas públicas de Sorocaba-SP. 2016. Dissertação (Mestrado em Educação) — Universidade Federal de São Carlos, São Carlos, 2016.

MATOS, W. M. M. Análise do Programa Ensino Médio Inovador no estado do Amapá no período de 2010 a 2014. 2015. Dissertação (Mestrado em Educação) Universidade Federal do Pará, Pará, 2015. 
MINISTÉRIO DA EDUCAÇÃO (MEC). Portaria $n^{\circ}$ 971, de 9 de outubro de 2009. Institui o Programa Ensino Médio Inovador, com vistas a apoiar e fortalecer o desenvolvimento de propostas curriculares inovadoras nas escolas do ensino médio não profissional. Brasilia, 2009.

MOFACTO, E. S. Curso de formação "Gestão Escolar para Resultados": uma análise à luz da experiência da implementação do Programa Ensino Médio Inovador em conjunto com o Programa Jovem do Futuro. Juiz de Fora, 2014.

NOGARA JUNIOR, G. O Programa Ensino Médio Inovador (PROEMI) no contexto das políticas do Banco Mundial (BM): rumo a formação de trabalhadores de novo tipo? 2015. Dissertação (Mestrado em Educação) — Universidade Federal de Florianópolis, Florianópolis, 2015.

PINTO, E. de V. A implementação do Programa Ensino Médio Inovador em uma escola estadual de Manaus: análise sobre o papel do professor articulador de projetos. 2016. Dissertação (Mestrado em Educação) - Universidade Federal de Juiz de Fora, Juiz de Fora, 2016.

ROCHA, H. O. Programa Ensino Médio Inovador - PROEMI no Maranhão: necessidades formativas de professores para o desenvolvimento de práticas pedagógicas inovadoras em escolas públicas de São Luís. 2016. Tese (Doutorado em Educação) - Universidade Federal do Rio Grande do Norte, Natal, 2016.

SAVIANI, D. O Choque Teórico da Politecnia. Trabalho, Educação e Saúde, v. 1, n. 1, 2003. Disponível em: 〈http://www.scielo.br/pdf/tes/v1n1/10.pdf〉. Acesso em: 30 set. 2015.

SOUSA JUNIOR, J. de. Omnilateralidade. In: PEREIRA, I. B.; LIMA, J. C. F. (Orgs.) Dicionário da educação profissional em saúde. 2 ed. rev. Ampl. Rio de Janeiro: EPSJV, 2008.

Recebido: 30/09/2018

Received: 09/30/2018

Aprovado: 29/10/2018

Approved: 10/29/2018 